\title{
Pathological Internet use among European adolescents: psychopathology and self-destructive behaviours
}

\author{
Michael Kaess · Tony Durkee $\cdot$ Romuald Brunner • Vladimir Carli $\cdot$ Peter Parzer • Camilla Wasserman • \\ Marco Sarchiapone $\cdot$ Christina Hoven - Alan Apter · Judit Balazs · Maria Balint · Julio Bobes • \\ Renaud Cohen • Doina Cosman • Padraig Cotter • Gloria Fischer • Birgitta Floderus • Miriam Iosue • \\ Christian Haring · Jean-Pierre Kahn · George J. Musa • Bogdan Nemes • Vita Postuvan · Franz Resch • \\ Pilar A. Saiz · Merike Sisask · Avigal Snir · Airi Varnik · Janina Žiberna · Danuta Wasserman
}

Received: 21 November 2013/Accepted: 15 May 2014/Published online: 3 June 2014

(C) The Author(s) 2014. This article is published with open access at Springerlink.com

\begin{abstract}
Rising global rates of pathological Internet use (PIU) and related psychological impairments have gained considerable attention in recent years. In an effort to acquire evidence-based knowledge of this relationship, the main objective of this study was to investigate the association between PIU, psychopathology and self-destructive behaviours among school-based adolescents in eleven European countries. This cross-sectional study was implemented within the framework of the European Union
\end{abstract}

Michael Kaess and Tony Durkee contributed equally to this paper and therefore both should be considered as first authors.

Electronic supplementary material The online version of this article (doi:10.1007/s00787-014-0562-7) contains supplementary material, which is available to authorized users.

M. Kaess · R. Brunner · P. Parzer · G. Fischer · F. Resch Section for Disorders of Personality Development, Clinic of Child and Adolescent Psychiatry, Centre for Psychosocial Medicine, University of Heidelberg, Heidelberg, Germany

T. Durkee · V. Carli · D. Wasserman $(\square)$

National Centre for Suicide Research and Prevention of Mental Ill-Health (NASP), Karolinska Institutet,

Stockholm, Sweden

e-mail: danuta.wasserman@ki.se

C. Wasserman · C. Hoven

Department of Child and Adolescent Psychiatry, New York State

Psychiatric Institute, Columbia University, New York, NY, USA

C. Wasserman · M. Sarchiapone $\cdot$ M. Iosue

Department of Health Sciences, University of Molise,

Campobasso, Italy

C. Hoven · G. J. Musa

Department of Epidemiology, Mailman School of Public Health,

Columbia University, New York, NY, US project: Saving and Empowering Young Lives in Europe. A representative sample of 11,356 school-based adolescents (M/F: 4,856/6,500; mean age: 14.9) was included in the analyses. PIU was assessed using the Young's Diagnostic Questionnaire. Psychopathology was measured using the Beck Depression Inventory-II, Zung Self-Rating Anxiety Scale and Strengths and Difficulties Questionnaire. Self-destructive behaviours were evaluated by the Deliberate Self-Harm Inventory and Paykel Suicide Scale. Results showed that suicidal behaviours (suicidal ideation and suicide attempts), depression, anxiety, conduct problems and hyperactivity/inattention were significant and independent predictors of PIU. The correlation between PIU, conduct problems and hyperactivity/inattention was stronger among females, while the link between PIU and symptoms of depression, anxiety and peer relationship

A. Apter · A. Snir

Feinberg Child Study Centre, Schneider Children's Medical

Centre, Tel Aviv University, Tel Aviv, Israel

J. Balazs

Vadaskert Child and Adolescent Psychiatric Hospital, Budapest, Hungary

J. Balazs

Institute of Psychology, Eotvos Lorand University, Budapest,

Hungary

M. Balint

Pedagogical and Psychological Counsel, Kobanya, Hungary

J. Bobes · P. A. Saiz

Department of Psychiatry, School of Medicine, Centro de Investigación Biomédica en Red de Salud Mental CIBERSAM, University of Oviedo, Oviedo, Spain

R. Cohen · J.-P. Kahn

Department of Psychiatry, Centre Hospitalo-Universitaire de NANCY, Université H. Poincaré, Nancy, France 
problems was stronger among males. The association between PIU, psychopathology and self-destructive behaviours was stronger in countries with a higher prevalence of PIU and suicide rates. These findings ascertain that psychopathology and suicidal behaviours are strongly related to PIU. This association is significantly influenced by gender and country suggesting socio-cultural influences. At the clinical and public health levels, targeting PIU among adolescents in the early stages could potentially lead to improvements of psychological well-being and a reduction of suicidal behaviours.

Keywords Pathological Internet use - Internet addiction Internet gaming disorder - SEYLE - Psychopathology · Suicidal behaviour

\section{Introduction}

The Internet is an integral part of modern society and functions as an essential medium for communication, socialization and education. Global rates of Internet use have increased considerably over the past few decades [1]. Though this trend is observed in all age groups, it is most pronounced among youth [2]. The expansion of interactive online activities appears to incite youth to stay online longer than anticipated [3, 4]. Excessive use of the Internet is known to increase the propensity for developing online addictive behaviours $[5,6]$. These high risk-behaviours could have a detrimental impact on adolescents' psychological development $[7,8]$.

\section{Cosman · B. Nemes}

Department of Clinical Psychology Department, Iuliu Hatieganu University of Medicine and Pharmacy, Cluj-Napoca, Romania

P. Cotter

National Suicide Research Foundation, Cork, Ireland

B. Floderus

Department of Clinical Neuroscience, Karolinska Institutet, Stockholm, Sweden

\section{Haring}

Research Division for Mental Health, University for Medical Information Technology (UMIT), Innsbruck, Austria

V. Postuvan $\cdot$ J. Žiberna

Health Research Department, PINT, University of Primorska, Koper, Slovenia

\section{Sisask · A. Varnik}

Estonian-Swedish Mental Health and Suicidology Institute, Centre of Behavioural and Health Science, Tallinn University, Tallinn, Estonia
Pathological Internet use (PIU) is conceptualized as an impulse-control disorder [9] and regarded as a taxonomy of behavioural addiction [10]. There is accumulating scientific-based evidence showing that PIU shares psychosocial, neurological, biological and genetic physiognomies with both pathological gambling and substance use disorders [11-16] with particular findings within Internet gaming $[17,18]$. In the recently published Diagnostic and Statistical Manual of Mental Disorders fifth edition (DSM-5), Internet gaming disorder was incorporated into Section III stipulating that further research was required [19]. In the new edition of the International Classification of Diseases (ICD-11), the WHO task force is considering the integration of behavioural addiction as a new diagnostic category with computer and Internet addiction as a subcategory [20]. The changes in nomenclature are potentially due to the mounting evidence suggesting PIU is associated with severe psychological impairment, particularly among youth $[21,22]$.

There are several cross-sectional studies indicating notable associations between PIU and symptoms of depression [23, 24], anxiety [25, 26], attention deficit hyperactivity disorder (ADHD) [27, 28], obsessive-compulsive disorder [29] and hostility/aggression [30]. Recent systematic reviews, however, have underlined a gap in knowledge due to methodological discrepancies and insufficient data concerning the relationship between PIU and comorbid psychopathology [31, 32].

Research shows that self-destructive behaviours are frequently observed among adolescents. These behaviours are typically interconnected with comorbid psychopathology $[33,34]$ and various types of risk-behaviours [35, 36]; however, little attention has been given to its potential link with PIU. The existing literature comprises limited evidence specifically assessing the liaison between PIU and self-destructive behaviours. Despite the ambiguity of research, there are a few studies indicating correlations between PIU and self-injurious behaviours (SIB) [37], suicidal ideation [38-40] and suicide attempts [41]. There are currently no studies identified in the literature examining this relationship using a cross-national European sample.

Given the limited data, studies using large and homogenous samples with reliable and validated psychometric measures are necessitated in order to assess the complex interaction between PIU, psychopathology and selfdestructive behaviours. Moreover, determining the influence of gender and country in this relationship will improve our understanding of the condition.

The present study is performed on a large, representative, cross-national sample of school-based adolescents in eleven European countries. The main objectives of this study were: (1) to investigate the association between PIU 
and psychopathological symptoms of depression, anxiety, emotional problems, conduct problems, hyperactivity/ inattention and peer relationship problems; (2) to examine the association between PIU and self-destructive behaviours including SIB, suicidal ideation and suicide attempts; and (3) to assess the influence of gender and country on the relationship between PIU, psychopathology and selfdestructive behaviours.

\section{Methods}

Study design and recruitment

The present cross-sectional study was performed within the framework of the European Union project: Saving and Empowering Young Lives in Europe (SEYLE) [42]. This randomized controlled trial (RCT) was implemented in eleven countries: Austria, Estonia, France, Germany, Hungary, Ireland, Israel, Italy, Romania, Slovenia and Spain with Sweden serving as the coordinating centre. The SEYLE sample comprised 12,395 school-based adolescents. Adolescents were recruited from randomly selected schools $(n=179)$ across study sites in each country according to specific inclusion and exclusion criteria [42]. Ethical approval was obtained from the local ethical committees in each respective country. Consent, response rates and representativeness of the sample were scrutinized and reported in a methodological analysis [43]. The analysis showed that study sites were reasonably representative of their respective country indicating a high external validity. Out of the initial sample of 12,395 students who completed the baseline questionnaire, 1,039 students were excluded due to missing data relevant for this study. The final sample comprised 11,356 school-based adolescents for the present study.

\section{Measurements}

Pathological Internet use (PIU) was assessed using the Young's Diagnostic Questionnaire (YDQ) [44]. The 8-item questionnaire has been found to be a reliable instrument for ascertaining PIU among adolescents [45]. The YDQ assesses patterns of Internet usage that result in psychological or social distress. The 8-item score reflects eight of the nine criteria for Internet gaming disorder in the DSM-5; however, the YDQ allows for the assessment of all online activities. Based on the YDQ total score, Internet users were categorized into three groups: adaptive Internet users (AIU) (scoring 0-2); maladaptive Internet users (MIU) (scoring 3-4); and pathological Internet users (PIU) (scoring $\geq 5$ ) [46].

The Beck Depression Inventory-II (BDI-II) [47] is a 21-item questionnaire used to measure depressive symptoms. A modified version of the BDI-II was used in the present study. One item "loss of libido" was removed from the scale as it was considered in some countries to be an inappropriate question for an adolescent population. Evidence shows that the omission of this question does not affect the reliability or validity of the BDI-II [48]. Our study confirmed this by showing a Cronbach's alpha coefficient of $(\alpha=0.86)$ [43]. Based on the BDI-II total score, students were categorized as having no depression (scoring 0-13), mild depression (scoring 14-19), moderate depression (scoring 20-28) and severe depression (scoring 29-63).

Anxiety was measured by the Zung Self-Rating Anxiety Scale (Z-SAS) [49]. Z-SAS is a 20-item assessment scale that measures state and trait anxiety. Based on the Z-SAS total score, adolescents were categorized as normal (scoring $\leq 44$ ), minimal to moderate anxiety (scoring 45-59), severe anxiety (scoring 60-74) and extreme anxiety (scoring $\geq 75$ ).

The Strengths and Difficulties Questionnaire (SDQ) [50] is a 25-item measure used for adolescents aged 11-17 years. The SDQ assesses emotional symptoms, conduct problems, hyperactivity/inattention, peer relationship problems and pro-social behaviour. The score is generated by summing items from all subscales. Based on the SDQ total score, students were categorized as normal (scoring 0-15), borderline (scoring 16-19) and severe (scoring 20-40).

A modified version of the Deliberate Self-Harm Inventory (DSHI) [51] was utilized to measure SIB. In the present study, different methods of SIB were combined to simplify and shorten the measure to a 6-item questionnaire [52]. SIB was rated positive in cases reporting $\geq 5$ events of SIB during their lifetime.

Suicidal behaviours (suicidal ideation and suicide attempts) were measured by the Paykel Suicide Scale (PSS) [53]. The PSS comprises the following five questions: during the past 2 weeks have you (i) felt that life was not worth living; (ii) wished you were dead; (iii) thought of taking your own life; (iv) seriously considered taking your own life or even made plans; and (v) have you tried to take your own life? A category of suicidal thoughts was defined by the answer "Yes" to the third (iii) and fourth (iv) question of the PSS (PSS score of 3-4). Suicide attempts were defined by the answer "Yes" to the last question (v) of the PSS (PSS score of 5).

\section{Statistical analyses}

The prevalence of categories in the BDI-II, Z-SAS, SDQ, DSHI and PSS was calculated independently for each Internet user group. To analyse the relationship between PIU (as the YDQ score), psychopathology and self 
destructive behaviours, multilevel mixed-effects linear regression with PIU as the dependent variable and age, gender, psychopathological scores (BDI-II, Z-SAS, SDQ) and categorical variables of self-destructive behaviours (DSHI, PSS) as level 1 fixed effects, school as level 2 random intercept and country as level 3 random intercept was performed. The estimation method was full ML with independent covariance structure. A subsequent stepwise reduction of the regression model was conducted in order to minimize the Bayes information criterion (BIC). We also explored possible interactions of the predictors with gender and country. Including all these interactions in one model would render a complex model with several estimation problems. Therefore, we analysed each predictor in a separate model with PIU as the dependent variable, the predictor, gender, country, interaction of predictor with gender and interaction of the predictor with country as level 1 fixed effects and school as level 2 random intercept. In the aforementioned, the estimation method was full ML with independent covariance structure. To avoid estimation problems due to cells with zeroes, we had to combine the categories "suicidal thoughts" and "suicide attempts" into one category "suicidal behaviours". All calculations were performed using the statistical software Stata 13.

\section{Results}

Characteristics of the sample

The final study sample comprised 11,356 adolescent students: 4,856 male $(42.8 \%)$ and 6,500 female $(57.2 \%)$ with a mean age of 14.9 years $(\mathrm{SD} \pm 0.88)$. The prevalence of MIU and PIU was 13.4 and $4.2 \%$, respectively. Females reported higher MIU (14.2\%) compared to males (12.3\%), while PIU was slightly higher among males $(4.7 \%)$ compared to females $(3.9 \%)$.

\section{Psychopathology and PIU}

In the AIU group $(n=9,355)$, results showed that the prevalence of moderate to severe depression and anxiety was $5 \%$, respectively. In the MIU group $(n=1,523)$, $17.1 \%$ were identified with moderate to severe depression and $16.4 \%$ with moderate to severe anxiety. In the PIU group $(n=478), 33.5 \%$ reported moderate to severe depression and $27.6 \%$ reported moderate to severe anxiety. The proportion of depression and anxiety was significantly higher in the MIU and PIU groups.

The prevalence of borderline and severe emotional symptoms was $10.8 \%$ for adaptive users, $23.7 \%$ for maladaptive users and $32 \%$ for pathological users. This pattern continued for the prevalence of conduct problems (17.5, 31.9, 41.0\%), hyperactivity/inattention $(15.1,28.2$, $37.2 \%)$, peer relationships $(12.6,21.6,31.2 \%)$ and low pro-social behaviours $(14.1,18.1,25.1 \%)$, respectively. The proportion of all borderline and severe categories was significantly higher in the MIU and PIU groups (see Supplement Table A for prevalence rates and statistics on group differences).

\section{Self-destructive behaviours and PIU}

The prevalence of SIB was $4.5 \%$ among adaptive users, $12.2 \%$ among maladaptive users and $22.2 \%$ among pathological users. These outcomes denote that SIB was nearly three times higher among maladaptive users and nearly five times higher among pathological users compared to adaptive users. A similar pattern was observed for the prevalence of suicidal ideation $(12.7,31.9$, $42.3 \%)$ and suicide attempts $(0.3,1.1,3.1 \%)$. The proportion of suicidal ideation was two and a half times higher among maladaptive users and three times higher among pathological users compared to adaptive users, while suicide attempts were nearly four times higher among maladaptive users and ten times higher among pathological users compared to adaptive users (see Supplement Table A).

The association between PIU and age, gender, psychopathology and self-destructive behaviours

Results from the multivariate regression analysis on age, gender, psychopathology and self-destructive behaviours among pathological users are presented in Table 1. Outcomes indicated a significant inverse correlation between female gender and PIU $(p<0.001)$. The strongest correlations within the psychopathological domain were observed between PIU and symptoms of depression $(p<0.001)$ and anxiety $(p<0.001)$. In the SDQ, notable correlations were observed between PIU and conduct problems $(p<0.001)$ and hyperactivity/ inattention $(p<0.001)$; however, no significant associations were found between PIU and emotional symptoms, peer relationship problems or low pro-social behaviours. In regards to self-destructive behaviours, SIB $(p=0.014)$, suicidal ideation $(p<0.001)$ and suicide attempts $(p=0.003)$ were significantly correlated with PIU.

The stepwise regression analysis resulted in a model that showed gender, symptoms of depression, anxiety, conduct problems, hyperactivity/inattention, suicidal ideation and suicide attempts were significant and independent predictors of PIU. SIB did not appear to be a significant factor in the final model (see Table 2). 
Table 1 Multivariate regression model on pathological Internet use (PIU) with age, gender, psychopathological scores and self-destructive behaviour categories as explaining variables

\begin{tabular}{|c|c|c|c|c|}
\hline \multirow[t]{2}{*}{ Psychopathology and self-destructive behaviours } & \multicolumn{4}{|c|}{ Pathological Internet use } \\
\hline & Coefficient & $95 \% \mathrm{CI}$ & Standardized coefficient $^{\mathrm{a}}$ & $p$ value \\
\hline Age & -0.014 & -0.048 to 0.020 & -0.009 & 0.426 \\
\hline Female gender & -0.086 & -0.141 to -0.032 & - & 0.002 \\
\hline Depression (BDI-score) & 0.032 & 0.027 to 0.037 & 0.166 & $<0.001$ \\
\hline Anxiety (Z-SAS-score) & 0.033 & 0.028 to 0.038 & 0.169 & $<0.001$ \\
\hline Emotional symptoms (SDQ-subscore) & -0.002 & -0.017 to 0.013 & -0.003 & 0.825 \\
\hline Conduct problems (SDQ-subscore) & 0.059 & 0.041 to 0.077 & 0.064 & $<0.001$ \\
\hline Hyperactivity and/or inattention (SDQ-subscore) & 0.057 & 0.044 to 0.070 & 0.084 & $<0.001$ \\
\hline Peer relationship problems (SDQ-subscore) & -0.007 & -0.024 to 0.009 & -0.008 & 0.375 \\
\hline Pro-social behaviour (SDQ-subscore) & -0.011 & -0.026 to 0.003 & -0.015 & 0.121 \\
\hline Self-injurious behaviour & 0.132 & 0.027 to 0.237 & - & 0.014 \\
\hline Suicidal ideation & 0.314 & 0.241 to 0.387 & - & $<0.001$ \\
\hline Suicide attempts & 0.530 & 0.185 to 0.875 & - & 0.003 \\
\hline \multicolumn{5}{|l|}{ Random-effects parameters } \\
\hline Country (variance of intercept) & 0.044 & 0.177 to 0.111 & & \\
\hline School (variance of intercept) & 0.032 & 0.022 to 0.049 & & \\
\hline
\end{tabular}

Young's Diagnostic Questionnaire (YDQ)

Model Wald $\chi^{2}(12)=2,605.9, p<0.0001$; LR test versus linear regression $\chi^{2}(2)=349.1, p<0.0001$, BIC $=37,976,94$

${ }^{a}$ The standardized coefficient of continuous predictor $x$ was calculated as coef $(x) \times \operatorname{SD}(x) / \operatorname{SD}(y)$

Table 2 Final model of the stepwise regression on pathological Internet use (PIU) with age, gender, psychopathological scores and suicidal behaviour categories as explaining variables

\begin{tabular}{|c|c|c|c|c|}
\hline \multirow[t]{2}{*}{ Psychopathology and self-destructive behaviours } & \multicolumn{4}{|c|}{ Pathological Internet use } \\
\hline & Coefficient & $95 \% \mathrm{CI}$ & $\begin{array}{l}\text { Standardized } \\
\text { coefficient }^{\mathrm{a}}\end{array}$ & $p$ value \\
\hline Female gender & -0.971 & -0.149 to -0.045 & & $<0.001$ \\
\hline Depression (BDI-score) & 0.033 & 0.028 to 0.038 & 0.168 & $<0.001$ \\
\hline Anxiety (Z-SAS-score) & 0.033 & 0.028 to 0.038 & 0.169 & $<0.001$ \\
\hline Conduct problems (SDQ-subscore) & 0.063 & 0.045 to 0.080 & 0.068 & $<0.001$ \\
\hline Hyperactivity and/or inattention (SDQ-subscore) & 0.059 & 0.046 to 0.071 & 0.086 & $<0.001$ \\
\hline Suicidal ideation & 0.324 & 0.251 to 0.397 & & $<0.001$ \\
\hline Suicide attempts & 0.552 & 0.207 to 0.896 & & 0.002 \\
\hline \multicolumn{5}{|l|}{ Random-effects parameters } \\
\hline Country (variance of intercept) & 0.043 & 0.172 to 0.108 & & \\
\hline School (variance of intercept) & 0.033 & 0.022 to 0.050 & & \\
\hline
\end{tabular}

Young's Diagnostic Questionnaire (YDQ)

Model Wald $\chi^{2}(7)=2,593.2, p<0.0001$; LR test versus linear regression $\chi^{2}(2)=357.96 .1, p<0.0001, \mathrm{BIC}=37,940.35$

${ }^{a}$ The standardized coefficient of continuous predictor $\mathrm{x}$ was calculated as $\operatorname{coef}(x) \times \operatorname{SD}(x) / \operatorname{SD}(y)$

Interactions of psychopathology and self-destructive behaviours with gender and country

The effect of gender and country on the relationship between PIU, psychopathology and self-destructive behaviours is presented in Table 3.
Results showed that gender had a significant effect on the relationship between PIU and symptoms of depression, anxiety, conduct problems, hyperactivity/inattention and peer relationship problems. The correlation between PIU and symptoms of depression, anxiety and peer relationship problems was stronger among males, whereas the link 
Table 3 Interactions of psychopathology and self-destructive behaviour with gender and country in the regression analysis of psychopathological scores and self-destructive behaviour categories on pathological Internet use (PIU)

\begin{tabular}{|c|c|c|c|c|c|c|c|}
\hline \multirow{2}{*}{$\begin{array}{l}\text { Psychopathology and self- } \\
\text { destructive behaviours } \\
\text { Variables }\end{array}$} & \multicolumn{2}{|c|}{$\begin{array}{l}\text { Interactions with } \\
\text { gender }\end{array}$} & \multirow{2}{*}{$\begin{array}{l}\text { Gender with stronger } \\
\text { association between } \\
\text { variables and YDQ- } \\
\text { score }\end{array}$} & \multicolumn{2}{|c|}{$\begin{array}{l}\text { Interactions with } \\
\text { country }\end{array}$} & \multirow{2}{*}{$\begin{array}{l}\text { Country with stronger } \\
\text { association between } \\
\text { variable and YDQ- } \\
\text { score }\end{array}$} & \multirow{2}{*}{$\begin{array}{l}\text { Country with weaker } \\
\text { association between } \\
\text { variable and YDQ- } \\
\text { score }\end{array}$} \\
\hline & $\begin{array}{l}\chi^{2} \\
(\mathrm{df}=1)\end{array}$ & $p$ value & & $\begin{array}{l}\chi^{2} \\
(\mathrm{df}=10)\end{array}$ & $p$ value & & \\
\hline Depression (BDI-score) & 19.28 & $<0.001$ & Male & 85.52 & $<0.001$ & Ireland & Italy \\
\hline Anxiety (Z-SAS score) & 10.53 & 0.001 & Male & 49.54 & $<0.001$ & Estonia & France \\
\hline $\begin{array}{l}\text { Emotional symptoms } \\
\text { (SDQ-subscore) }\end{array}$ & 1.89 & 0.169 & - & 47.52 & $<0.001$ & Estonia & Hungary \\
\hline $\begin{array}{l}\text { Conduct problems (SDQ- } \\
\text { subscore) }\end{array}$ & 6.26 & 0.012 & Female & 28.74 & 0.001 & Ireland & Italy \\
\hline $\begin{array}{l}\text { Hyperactivity and/or } \\
\text { inattention (SDQ- } \\
\text { subscore) }\end{array}$ & 13.62 & $<0.001$ & Female & 50.59 & $<0.001$ & Slovenia & Israel \\
\hline $\begin{array}{l}\text { Peer relationship problems } \\
\text { (SDQ-subscore) }\end{array}$ & 8.16 & 0.004 & Male & 19.17 & 0.038 & Ireland & France \\
\hline $\begin{array}{l}\text { Pro-social behaviour } \\
\text { (SDQ-subscore) }\end{array}$ & 3.04 & 0.081 & - & 10.07 & 0.435 & - & - \\
\hline $\begin{array}{l}\text { Self-injurious behaviour } \\
\text { (Category of } 5 \text { or more } \\
\text { incidents of self-harm in } \\
\text { the DSHI) }\end{array}$ & 0.05 & 0.831 & - & 46.75 & $<0.001$ & Ireland & Slovenia \\
\hline $\begin{array}{l}\text { Suicidal behaviour } \\
\text { (Category of suicidal } \\
\text { thoughts and suicide } \\
\text { attempts in the PSS) }\end{array}$ & 0.35 & 0.553 & - & 90.19 & $<0.001$ & Estonia & Italy \\
\hline
\end{tabular}

Young's Diagnostic Questionnaire (YDQ)

between conduct problems, hyperactivity/inattention and PIU was stronger among females. No significant gender interactions were found with regards to self-destructive behaviours.

Significant cross-national interactions showed that country markedly influenced the relationship between PIU, psychopathology and self-destructive behaviours. The correlation between PIU, psychopathology and selfdestructive behaviours was strongest in Estonia and Ireland, while the weakest correlations were observed in France, Italy and Hungary.

\section{Discussion}

Pathological Internet use (PIU) appears to be strongly correlated with comorbid psychopathology and suicidal behaviours. Results revealed that the prevalence of psychopathology and self-destructive behaviours was higher among pathological users compared to both adaptive and maladaptive users. Given addiction is a chronic and progressive disease [54], identifying and treating individuals in the earlier stages can theoretically prevent further escalation into a fully developed addiction, psychopathological disorder or suicidal behaviour. In this context, tracing the development of maladaptive patterns of Internet use provides the opportunity to intervene before these behaviours become pathological.

In the final stepwise regression analysis, results showed that symptoms of depression, anxiety, conduct problems, hyperactivity/inattention and suicidal behaviours were significant and independent predictors of PIU. If adolescents have pre-existing psychopathological symptoms, then the Internet could serve as means to avoid or escape from psychological distress. Coping strategies are an effort to solve personal and interpersonal problems in order to escape, avoid or minimize stress levels [55]. Thompson et al. [56] suggest that there are two types of coping strategies involved in depressive states: (i) adaptive coping (i.e., strategies that reduce stress levels) and (ii) maladaptive coping (i.e., strategies that induce stress levels). Yen and colleagues [57] noted that the level of hostility and depression among subjects markedly decreased as soon as they went online. This outcome infers that Internet use could develop into a maladaptive coping strategy. On the other hand, it could be hypothesized that students exhibit precipitating symptoms of psychopathology or suicidal behaviours as a result of their online experiences. Research examining the pathway of this relationship is needed. The role of psychopathology and suicidal behaviours at 
different stages of Internet use is important to understand. If mental disorders are treated in the earlier stages, this is known to delay or prevent subsequent suicidal acts [58]. The same reasoning could apply to targeting early symptoms of PIU among adolescents.

Adolescents with conduct problems and hyperactivity/ inattention are often impulsive [59, 60]. Impulsivity is an important trait in the context of suicidal behaviours [61, 62]. As PIU is considered to be an impulse-control disorder, conditions associated with impulsivity are expected to be present among pathological users, which is clearly supported by our findings. In this regard, PIU seems to show considerable similarities with substance use to which there is strong evidence showing significant correlations with psychopathology, suicidal behaviours and impulsivity $[63,64]$. A recent review argued that certain traits as impulsivity are potential endophenotypes of a variety of mental health problems [65]. These underlying character traits could be essential in the development of PIU and may explain the robust associations observed between PIU and impulsive-related emotional and behavioural problems and suicidal behaviours in the present study. Further investigations on PIU and personality traits could help to characterize and identify at-risk groups in the early stages of addiction in order to facilitate prevention efforts.

Our results showed that male students experiencing symptoms of depression, anxiety and peer relationship problems were more likely to be identified as pathological users; however, these symptoms are known to occur more often in females [66, 67]. Female students experiencing conduct problems or hyperactivity/inattention were more likely to be identified as pathological users; however, these behaviours are known to be more prevalent among males $[68,69]$. These outcomes infer that suffering from atypical gender-specific problems appears to be significantly associated with PIU. It could be postulated that males and females exhibit different pathways in the development of PIU.

Our findings revealed that country significantly influenced the association between PIU, psychopathology and self-destructive behaviours. The correlation between PIU, psychopathology and self-destructive behaviours was strongest in Estonia and Ireland, while the weakest was found in France, Italy and Hungary. This corresponds with the prevalence of PIU in these respective countries [70]. The observed trend also corresponds to the national suicide rates among these respective countries. In 2010, suicide rates were higher among those aged 15-19 years in Estonia $(12.8 \%)$ and Ireland $(10.8 \%)$ compared to adolescents in France $(4.9 \%)$, Italy $(1.9 \%)$ and Hungary (5.9\%) [71]. These results infer that country could be a moderating factor in the correlation between PIU, psychopathology and self-destructive behaviours. The moderating role of country could be due to genetic variability or the notable effect of socio-cultural influences. Socio-cultural factors as cultural identity, family structure and gender roles are known to affect adolescent behaviours [72, 73] and psychological well-being [74]. Online addictive behaviours and related psychopathological features observed among adolescents could be a reflection of the internalized values and beliefs expressed in their respective country. Research explicitly assessing the moderating role of intercultural influences in the development of PIU and psychopathology is still lacking and necessitates further investigations.

To our knowledge, this is the first epidemiological study to investigate the association between PIU, psychopathology and self-destructive behaviours within a cross-national European context. Research in this field has been hampered by methodological weaknesses, whereof the most prominent has been sampling bias. The majority of previous studies frequently relied on convenience sampling through voluntary Internet surveys (e.g., chat rooms) without measurable denominators. The novelty of this study is the large, representative, cross-national sample of European adolescents. The standardized and homogenous methodology used to collect the data is also a major strength of the study. Given the study sites were representative of the respective country allows for a higher degree of generalizability of the findings. Limitations of the study included the cross-sectional design, which provides no indication of the sequence of events and is unable to infer causality. Data were collected through self-reported questionnaires, which are susceptible to information bias.

\section{Conclusions}

Results showed that symptoms of depression, hyperactivity/inattention, conduct problems and suicidal behaviours are significant and independent predictors of PIU. Suicidal behaviours, depression and anxiety proved to be the strongest predictors of PIU. This interaction is significantly influenced by gender and country suggesting sociocultural influences. At the clinical and public health levels, targeting PIU among adolescents in the early stages could potentially lead to improvements of psychological wellbeing and a reduction of suicidal behaviours.

Acknowledgments The SEYLE project is supported through Coordination Theme 1 (Health) of the European Union Seventh Framework Program (FP7), Grant agreement nr HEALTH-F2-2009223091. The authors were independent of the funders in all aspects of study design, data analysis and writing of this manuscript. The Project Leader and Coordinator of the SEYLE project is Professor in Psychiatry and Suicidology Danuta Wasserman, Karolinska Institute (KI), Head of the National Centre for Suicide Research and Prevention of Mental Ill-Health and Suicide (NASP), at KI, Stockholm, Sweden. Other members of the Executive Committee are Professor 
Marco Sarchiapone, Department of Health Sciences, University of Molise, Campobasso, Italy; Senior Lecturer Vladimir Carli, National Centre for Suicide Research and Prevention of Mental Ill-Health (NASP), Karolinska Institute, Stockholm, Sweden; Professor Christina W. Hoven and Anthropologist Camilla Wasserman, Department of Child and Adolescent Psychiatry, New York State Psychiatric Institute, Columbia University, New York, USA. The SEYLE Consortium comprises centres in 12 European countries. Site leaders for each respective centre and country are: Danuta Wasserman (NASP, Karolinska Institute, Sweden, Coordinating Centre), Christian Haring (University for Medical Information Technology, Austria), Airi Varnik (Estonian-Swedish Mental Health \& Suicidology Institute, Estonia), Jean-Pierre Kahn (University of Nancy, France), Romuald Brunner (University of Heidelberg, Germany), Judit Balazs (Vadaskert Child and Adolescent Psychiatric Hospital, Hungary), Paul Corcoran (National Suicide Research Foundation, Ireland), Alan Apter (Schneider Children's Medical Centre of Israel, Tel Aviv University, Tel Aviv, Israel), Marco Sarchiapone (University of Molise, Italy), Doina Cosman (Iuliu Hatieganu University of Medicine and Pharmacy, Romania), Vita Postuvan (University of Primorska, Slovenia) and Julio Bobes (University of Oviedo, Spain). Support for "Ethical Issues in Research with Minors and other Vulnerable Groups" was obtained by a grant from the Botnar Foundation, Basel, for Professor of Ethics, Dr. Stella Reiter-Theil, Psychiatric Clinic at Basel University, who served as the independent ethical consultant to the SEYLE project.

Conflict of interest The authors declare that they have no conflict of interest.

Ethical standards The study has been approved by the appropriate ethics committee of each study centre and has therefore been performed in accordance with the ethical standards laid down in the 1964 Declaration of Helsinki and its later amendments.

Open Access This article is distributed under the terms of the Creative Commons Attribution License which permits any use, distribution, and reproduction in any medium, provided the original author(s) and the source are credited.

\section{References}

1. International Telecommunication Union (2013) World Telecommunication/ICT Indicators Database 2013 (17th edn)

2. Seybert $H$ (2012) Internet use in households and by individuals in 2012. Ind Trade Serv 50:2

3. Smahel D, Blinka L, Ledabyl O (2008) Playing MMORPGs: connections between addiction and identifying with a character. Cyberpsychol Behav 11(6):715-718. doi:10.1089/cpb.2007.0210

4. Fioravanti G, Dettore D, Casale S (2012) Adolescent Internet addiction: testing the association between self-esteem, the perception of Internet attributes, and preference for online social interactions. Cyberpsychol Behav Soc Netw 15(6):318-323. doi:10.1089/cyber.2011.0358

5. Tonioni F, D'Alessandris L, Lai C, Martinelli D, Corvino S, Vasale M, Fanella F, Aceto P, Bria P (2012) Internet addiction: hours spent online, behaviors and psychological symptoms. Gen Hosp Psychiatry 34(1):80-87. doi:10.1016/j.genhosppsych.2011. 09.013

6. Tsitsika A, Critselis E, Kormas G, Filippopoulou A, Tounissidou D, Freskou A, Spiliopoulou T, Louizou A, Konstantoulaki E, Kafetzis D (2009) Internet use and misuse: a multivariate regression analysis of the predictive factors of internet use among
Greek adolescents. Eur J Pediatr 168(6):655-665. doi:10.1007/ s00431-008-0811-1

7. Iacovelli A, Valenti S (2009) Internet addiction's effect on likeability and rapport. Comput Hum Behav 25(2):439-443. doi:10. 1016/j.chb.2008.10.006

8. Gackenbach J (2011) Psychology and the Internet: intrapersonal, interpersonal, and transpersonal implications. Academic Press, San Diego

9. Young KS (1999) Internet addiction: symptoms, evaluation and treatment. Innovations in clinical practice: a source book, vol 17, pp 19-31

10. Griffiths M (2000) Internet addiction-time to be taken seriously? Addict Res Theory 8(5):413-418

11. Brezing C, Derevensky JL, Potenza MN (2010) Non-substanceaddictive behaviors in youth: pathological gambling and problematic Internet use. Child Adolesc Psychiatr Clin N Am 19(3):625-641. doi:10.1016/j.chc.2010.03.012

12. Goldstein RZ, Volkow ND (2011) Dysfunction of the prefrontal cortex in addiction: neuroimaging findings and clinical implications. Nat Rev Neurosci 12(11):652-669

13. Montag C, Kirsch P, Sauer C, Markett S, Reuter M(2012) The role of the CHRNA4 gene in Internet addiction: a case-control study. J Addict Med 6(3):191-195. doi:10.1097/ADM.0b013e31825ba7e7

14. Kormas G, Critselis E, Janikian M, Kafetzis D, Tsitsika A (2011) Risk factors and psychosocial characteristics of potential problematic and problematic internet use among adolescents: a crosssectional study. BMC Public Health 11:595. doi:10.1186/14712458-11-595

15. Zhou Y, Lin FC, Du YS, Qin LD, Zhao ZM, Xu JR, Lei H (2011) Gray matter abnormalities in Internet addiction: a voxel-based morphometry study. Eur J Radiol 79(1):92-95. doi:10.1016/j. ejrad.2009.10.025

16. Grant JE, Potenza MN, Weinstein A, Gorelick DA (2010) Introduction to behavioral addictions. Am J Drug Alcohol Abuse 36(5):233-241. doi:10.3109/00952990.2010.491884

17. Han DH, Bolo N, Daniels MA, Arenella L, Lyoo IK, Renshaw PF (2011) Brain activity and desire for Internet video game play. Compr Psychiatry 52(1):88-95

18. Ko CH, Liu GC, Hsiao S, Yen JY, Yang MJ, Lin WC, Yen CF, Chen CS (2009) Brain activities associated with gaming urge of online gaming addiction. J Psychiatr Res 43(7):739-747. doi:10. 1016/j.jpsychires.2008.09.012

19. American Psychiatric Association (APA) (2013) Diagnostic and statistical manual of mental disorders (DSM-5). http://www. dsm5.org

20. Mann K, Fauth-Buhler M, Seiferth N, Heinz A, Expertengruppe Verhaltenssuchte der D (2013) The concept of behavioral addiction and limits of the term addiction. Nervenarzt 84(5):548-556. doi:10.1007/s00115-012-3718-z

21. van den Eijnden RJ, Meerkerk GJ, Vermulst AA, Spijkerman R, Engels RC (2008) Online communication, compulsive Internet use, and psychosocial well-being among adolescents: a longitudinal study. Dev Psychol 44(3):655-665. doi:10.1037/0012-1649. 44.3.655

22. Tsitsika A, Critselis E, Louizou A, Janikian M, Freskou A, Marangou E, Kormas G, Kafetzis D (2011) Determinants of internet addiction among adolescents: a case-control study. Thescientificworldjournal 11:866-874. doi:10.1100/tsw.2011.85

23. Andreou E, Svoli H (2013) The association between internet user characteristics and dimensions of internet addiction among Greek adolescents. Int J Ment Health Addict 11(2):139-148. doi:10. 1007/s11469-012-9404-3

24. Sasmaz T, Oner S, Kurt AO, Yapici G, Yazici AE, Bugdayci R, Sis M (2014) Prevalence and risk factors of Internet addiction in high school students. Eur J Pub Health 24(1):15-20. doi:10.1093/ eurpub/ckt051 
25. Zboralski K, Orzechowska A, Talarowska M, Darmosz A, Janiak A, Janiak M, Florkowski A, Galecki P (2009) The prevalence of computer and Internet addiction among pupils. Postepy Hig Med Dosw (Online) 63:8-12

26. Lee BW, Stapinski LA (2012) Seeking safety on the internet: relationship between social anxiety and problematic internet use. J Anxiety Disord 26(1):197-205. doi:10.1016/j.janxdis.2011.11. 001

27. Gundogar A, Bakim B, Ozer OA, Karamustafalioglu O (2012) The association between internet addiction, depression and ADHD among high school students. Eur Psychiatry 27:1

28. Yoo HJ, Cho SC, Ha J, Yune SK, Kim SJ, Hwang J, Chung A, Sung YH, Lyoo IK (2004) Attention deficit hyperactivity symptoms and internet addiction. Psychiatry Clin Neurosci 58(5):487-494. doi:10.1111/j.1440-1819.2004.01290.x

29. Cecilia MR, Mazza M, Cenciarelli S, Grassi M, Cofini V (2013) The relationship between compulsive behaviour and internet addiction. Styles of Commun 5(1):24-31

30. Adalier A, Balkan E (2012) The relationship between internet addiction and psychological symptoms. Int $\mathbf{J}$ Global Educat 1(2):42-49

31. Moreno MA, Jelenchick L, Cox E, Young H, Christakis DA (2011) Problematic internet use among US youth: a systematic review. Arch Pediatr Adolesc Med 165(9):797-805. doi:10.1001/ archpediatrics.2011.58

32. Carli V, Durkee T, Wasserman D, Hadlaczky G, Despalins R, Kramarz E, Wasserman C, Sarchiapone M, Hoven CW, Brunner R, Kaess M (2013) The association between pathological internet use and comorbid psychopathology: a systematic review. Psychopathology 46(1):1-13. doi:10.1159/000337971

33. Brunner R, Parzer P, Haffner J, Steen R, Roos J, Klett M, Resch F (2007) Prevalence and psychological correlates of occasional and repetitive deliberate self-harm in adolescents. Arch Pediatr Adolesc Med 161(7):641-649

34. Christiansen E, Larsen KJ (2012) Young people's risk of suicide attempts after contact with a psychiatric department-a nested case-control design using Danish register data. J Child Psychol Psychiatry 53(1):16-25

35. Clarke DE, Eaton WW, Petronis KR, Ko JY, Chatterjee A, Anthony JC (2010) Increased risk of suicidal ideation in smokers and former smokers compared to never smokers: evidence from the Baltimore ECA follow-up study. Suicide Life Threat Behav 40(4):307-318

36. Bossarte RM, Swahn MH (2011) The associations between early alcohol use and suicide attempts among adolescents with a history of major depression. Addict Behav 36(5):532-535

37. Lam LT, Peng Z, Mai J, Jing J (2009) The association between internet addiction and self-injurious behaviour among adolescents. Injury Prev J Int Soc Child Adolesc Injury Prev 15(6):403-408. doi:10.1136/ip.2009.021949

38. Park S, Hong KE, Park EJ, Ha KS, Yoo HJ (2012) The association between problematic internet use and depression, suicidal ideation and bipolar disorder symptoms in Korean adolescents. Aust N Z J Psychiatry. doi:10.1177/0004867412463613

39. Kim K, Ryu E, Chon MY, Yeun EJ, Choi SY, Seo JS, Nam BW (2006) Internet addiction in Korean adolescents and its relation to depression and suicidal ideation: a questionnaire survey. Int $\mathbf{J}$ Nurs Stud 43(2):185-192. doi:10.1016/j.ijnurstu.2005.02.005

40. Fu KW, Chan WS, Wong PW, Yip PS (2010) Internet addiction: prevalence, discriminant validity and correlates among adolescents in Hong Kong. Br J Psychiatry 196(6):486-492. doi:10. 1192/bjp.bp.109.075002

41. Lin IH, Ko CH, Chang YP, Liu TL, Wang PW, Lin HC, Huang MF, Yeh YC, Chou WJ, Yen CF (2014) The association between suicidality and internet addiction and activities in Taiwanese adolescents. Compr Psychiatry 55(3):504-510. doi:10.1016/j. comppsych.2013.11.012

42. Wasserman D, Carli V, Wasserman C, Apter A, Balazs J, Bobes $\mathrm{J}$, Bracale R, Brunner R, Bursztein-Lipsicas C, Corcoran P, Cosman D, Durkee T, Feldman D, Gadoros J, Guillemin F, Haring C, Kahn JP, Kaess M, Keeley H, Marusic D, Nemes B, Postuvan V, Reiter-Theil S, Resch F, Saiz P, Sarchiapone M, Sisask M, Varnik V, Hoven CW (2010) Saving and Empowering Young Lives in Europe (SEYLE): a randomized controlled trial. BMC Public Health 10(1):192

43. Carli V, Wasserman C, Wasserman D, Sarchiapone M, Apter A, Balazs J, Bobes J, Brunner R, Corcoran P, Cosman D, Guillemin F, Haring C, Kaess M, Kahn JP, Keeley H, Kereszteny A, Iosue M, Mars U, Musa G, Nemes B, Postuvan V, Reiter-Theil S, Saiz P, Varnik P, Varnik A, Hoven CW (2013) The saving and empowering young lives in Europe (SEYLE) randomized controlled trial (RCT): methodological issues and participant characteristics. BMC Public Health 13:479. doi:10.1186/1471-245813-479

44. Young KS (1998) Internet addiction: the emergence of a new clinical disorder. Cyberpsychol Behav 1(3):237-244

45. Siomos KE, Dafouli ED, Braimiotis DA, Mouzas OD, Angelopoulos NV (2008) Internet addiction among Greek adolescent students. Cyberpsychol Behav 11(6):653-657. doi:10.1089/cpb. 2008.0088

46. Johansson A, Gotestam KG (2004) Internet addiction: characteristics of a questionnaire and prevalence in Norwegian youth (12-18 years). Scand J Psychol 45(3):223-229. doi:10.1111/j. 1467-9450.2004.00398.x

47. Beck AT, Steer RA, Ball R, Ranieri W (1996) Comparison of beck depression inventories-IA and -II in psychiatric outpatients. J Pers Assess 67(3):588-597. doi:10.1207/s15327752jpa6703_13

48. Byrne BM, Stewart SM, Lee PW (2004) Validating the Beck depression inventory-II for Hong Kong community adolescents. Int J Test 4(3):199-216

49. Zung WW (1971) A rating instrument for anxiety disorders. Psychosomatics 12(6):371-379

50. Goodman R, Meltzer H, Bailey V (1998) The strengths and difficulties questionnaire: a pilot study on the validity of the selfreport version. Eur Child Adolesc Psychiatry 7(3):125-130

51. Gratz KL (2001) Measurement of deliberate self-harm: preliminary data on the Deliberate Self-Harm Inventory. J Psychopathol Behav Assess 23(4):253-263

52. Brunner R, Kaess M, Parzer P, Fischer G, Carli V, Hoven CW, Wasserman C, Sarchiapone M, Resch F, Apter A, Balazs J, Barzilay S, Bobes J, Corcoran P, Cosmanm D, Haring C, Iosuec M, Kahn J-P, Keeley H, Meszaros G, Nemes B, Podlogar T, Postuvan V, Saiz PA, Sisask M, Tubiana A, Varnik A, Wasserman D (2014) Life-time prevalence and psychosocial correlates of adolescent direct self-injurious behavior: a comparative study of findings in 11 European countries. J Child Psychol Psychiatry 55(4):337-348. doi:10.1111/jcpp.12166

53. Paykel E, Myers J, Lindenthal J, Tanner J (1974) Suicidal feelings in the general population: a prevalence study. Br J Psychiatry 124(582):460-469

54. Morse RM, Flavin DK (1992) The definition of alcoholism. JAMA 268(8):1012-1014

55. Carver CS, Connor-Smith J (2010) Personality and coping. Annu Rev Psychol 61:679-704

56. Thompson RJ, Mata J, Jaeggi SM, Buschkuehl M, Jonides J, Gotlib IH (2010) Maladaptive coping, adaptive coping, and depressive symptoms: variations across age and depressive state. Behav Res Ther 48(6):459-466

57. Yen JY, Yen CF, Wu HY, Huang CJ, Ko CH (2011) Hostility in the real world and online: the effect of internet addiction, 
depression, and online activity. Cyberpsychol Behav Soc Netw 14(11):649-655. doi:10.1089/cyber.2010.0393

58. Sadler L (1991) Depression in adolescents. Context, manifestations, and clinical management. Nurs Clinics N Am 26(3): $559-572$

59. Kofler MJ, Rapport MD, Bolden J, Sarver DE, Raiker JS, Alderson RM (2011) Working memory deficits and social problems in children with ADHD. J Abnorm Child Psychol 39(6):805-817

60. Skounti M, Giannoukas S, Dimitriou E, Nikolopoulou S, Linardakis E, Philalithis A (2010) Prevalence of attention deficit hyperactivity disorder in schoolchildren in Athens, Greece. Association of ADHD subtypes with social and academic impairment. ADHD Atten Deficit Hyperact Disord 2(3):127-132

61. McCloskey MS, Look AE, Chen EY, Pajoumand G, Berman ME (2012) Nonsuicidal Self-Injury: relationship to behavioral and self-rating measures of impulsivity and self-aggression. Suicide Life Threat Behav 42(2):197-209

62. Kasen S, Cohen P, Chen H (2011) Developmental course of impulsivity and capability from age 10 to age 25 as related to trajectory of suicide attempt in a community cohort. Suicide Life Threat Behav 41(2):180-192

63. Storr CL, Pacek LR, Martins SS (2013) Substance use disorders and adolescent psychopathology. Public Health Rev 34(2):442-484

64. Pompili M, Serafini G, Innamorati M, Biondi M, Siracusano A, Di Giannantonio M, Giupponi G, Amore M, Lester D, Girardi P (2012) Substance abuse and suicide risk among adolescents. Eur Arch Psychiatry Clin Neurosci 262(6):469-485

65. Robbins TW, Gillan CM, Smith DG, de Wit S, Ersche KD (2012) Neurocognitive endophenotypes of impulsivity and compulsivity: towards dimensional psychiatry. Trends Cogn Sci 16(1):81-91

66. Kaess M, Parzer P, Haffner J, Steen R, Roos J, Klett M, Brunner R, Resch F (2011) Explaining gender differences in non-fatal suicidal behaviour among adolescents: a population-based study. BMC Public Health 11(1):597

67. Beautrais AL (2002) Gender issues in youth suicidal behaviour. Emerg Med 14(1):35-42

68. Fergusson DM, Horwood LJ (2002) Male and female offending trajectories. Dev Psychopathol 14(1):159-177

69. Rucklidge JJ (2010) Gender differences in attention-deficit/ hyperactivity disorder. Psychiatr Clin North Am 33(2):357-373

70. Durkee T, Kaess M, Carli V, Parzer P, Wasserman C, Floderus B, Apter A, Balazs J, Barzilay S, Bobes J, Brunner R, Corcoran P, Cosman D, Cotter P, Despalins R, Graber N, Guillemin F, Haring C, Kahn JP, Mandelli L, Marusic D, Meszaros G, Musa GJ, Postuvan V, Resch F, Saiz PA, Sisask M, Varnik A, Sarchiapone M, Hoven CW, Wasserman D (2012) Prevalence of pathological internet use among adolescents in Europe: demographic and social factors. Addiction 107(12):2210-2222. doi:10.1111/j. 1360-0443.2012.03946.x

71. Eurostat (2010) Causes of death. http://epp.eurostat.ec.europa.eu/ portal/page/portal/eurostat/home/. Accessed March 252014

72. Siomos K, Floros G, Fisoun V, Evaggelia D, Farkonas N, Sergentani E, Lamprou M, Geroukalis D (2012) Evolution of Internet addiction in Greek adolescent students over a two-year period: the impact of parental bonding. Eur Child Adolesc Psychiatry 21(4):211-219. doi:10.1007/s00787-012-0254-0

73. McElhaney KB, Allen JP (2012) Sociocultural perspectives on adolescent autonomy. Adolescence and beyond: family processes and development, pp 161-176

74. Lopez SR, Guarnaccia PJ (2000) Cultural psychopathology: uncovering the social world of mental illness. Annu Rev Psychol 51:571-598. doi:10.1146/annurev.psych.51.1.571 